\title{
1 Comparative whole-genome approach to identify bacterial traits for microbial interactions
}

4 Luca Zoccarato*a, Daniel Sher*b, Takeshi Miki ${ }^{\mathrm{c}}$, Daniel Segrè ${ }^{\mathrm{d}, \mathrm{e}}$, Hans-Peter Grossart*a,f,g

6 (a) Department Experimental Limnology, Leibniz Institute of Freshwater Ecology and Inland Fisheries (IGB),

716775 Stechlin, Germany

8 (b) Department of Marine Biology, Leon H. Charney School of Marine Sciences, University of Haifa, 3498838

9 Haifa, Israel

10 (c) Department of Environmental Solution Technology, Ryukoku University, 612-8577 Kyoto, Japan

11 (d) Departments of Biology, Biomedical Engineering, Physics, Boston University, 02215 Boston, MA

12 (e) Bioinformatics Program \& Biological Design Center, Boston University, 02215 Boston, MA

13 (f) Berlin-Brandenburg Institute of Advanced Biodiversity Research (BBIB), 14195 Berlin, Germany

14 (g) Institute of Biochemistry and Biology, Potsdam University, 14476 Potsdam, Germany

\section{Corresponding authors $(*)$}

Luca Zoccarato, zoccarato@igb-berlin.de; Daniel Sher, dsher@univ.haifa.ac.il; Hans-Peter Grossart, hgross-

18 art@igb-berlin.de

\section{Abstract}

22 Microbial interactions shape the structure and function of microbial communities with profound

23 consequences for biogeochemical cycles and ecosystem health. Yet, most interaction mechanisms

24 are studied only in model systems and their prevalence is unknown. To systematically explore the

25 functional and interaction potential of sequenced marine bacteria, we developed a new trait-

26 based approach, and applied it to 473 complete genomes (248 genera), representing a significant

27 fraction of marine microbial communities. We identified genome functional clusters (GFCs) which

28 condense bacterial diversity into groups with potentially common ecology and life history. Most 
29 GFCs revealed unique combinations of interaction traits, some widely distributed (e.g., antimicro-

30 bial activity), others less common (e.g., production of siderophores and phytohormones, biosyn-

31 thesis and export of specific B vitamins). Specific GFCs, comprising Alpha- and Gammaproteobac-

32 teria, are predicted to preferentially interact synergistically and/or antagonistically with bacteria

33 and phytoplankton. Moreover, linked trait clusters (LTCS) identify traits that may have evolved to-

34 gether and point to specific modes of interactions. Our approach translates multidimensional gen-

35 omic information into an atlas of marine bacteria and their ecosystem functions, relevant for un-

36 derstanding the fundamental rules that govern community assembly and dynamics.

\section{Keywords}

40 marine bacteria; functional clusters; genetic traits; interaction mechanisms, B vitamins;

41 siderophores; phytohormones; motility and chemotaxis; secretion systems; antimicrobial com-

42 pounds

\section{Introduction}

46 Interactions among aquatic microorganisms such as symbiosis, parasitism, predation and competition,

47 greatly shape the composition and activity of microbial communities ${ }^{1-3}$. In particular, interactions between

48 heterotrophic bacteria and primary producers (phytoplankton) influence the growth of both organisms

494,5 with consequences for the ecosystem functioning and the biogeochemical cycles ${ }^{6,7}$. For instance, hetero-

50 trophic bacteria consume up to $50 \%$ of the organic matter released by phytoplankton, significantly affecting

51 the dynamics of the huge pool of dissolved organic carbon in the oceans ${ }^{8}$. Thus, if and how a bacterium can

52 interact with other microorganisms may have important consequences for the biological carbon pump in

53 the current and future oceans ${ }^{9,10}$. 
54 Studies using specific model organisms in binary co-cultures have started to elucidate mechanisms underly-

55 ing marine microbial interactions (mostly between bacteria and phytoplankton) ${ }^{1,2,5}$. Although these results

56 do not reflect the complexity of natural environments and the potential for higher-order effects ${ }^{11}$, they al-

57 low to identify the chemical signals and resulting changes in gene expression and physiology that underlie

58 these interactions. For example, bacteria associated with phytoplankton (e.g. within the phycosphere, ${ }^{5,12}$ )

59 gain access to labile organic carbon released by the primary producers, e.g. amino acids and small sulfur-

60 containing compounds ${ }^{13-18}$. In return, phytoplankton benefit from an increased accessibility to nutrients via

61 bacteria-mediated processes, e.g. nitrogen and phosphorus remineralization ${ }^{19}$, vitamin supply ${ }^{14,20}$ and iron

62 scavenging via formation of siderophores ${ }^{21,22}$. In addition to such metabolic interactions, direct signalling

63 may also occur between bacteria and phytoplankton, with heterotrophic bacteria directly controlling the

64 phytoplankton cell cycle through phytohormones ${ }^{13,23}$ or harming it via toxins ${ }^{18,24}$. Through such specific in-

65 fochemical-mediated interactions, bacteria may also directly affect the release rate of organic carbon from

66 phytoplankton, as well as rates of mortality and aggregation ${ }^{18,23,25}$.

67 While much is known about microbial interactions involving model organisms such as specific strains of Ros-

68 eobacter ${ }^{13,18-20,24}$, Alteromonas ${ }^{26-28}$, Cyanobacteria ${ }^{19,29}$ or Vibrio ${ }^{30,31}$, relatively little is known regarding how

69 widely distributed such interactions are across microbial diversity. The few experimental studies that meas-

70 ure microbial interactions across diversity (e.g. ${ }^{32-34}$ ) are usually limited in their phylogenetic scope and are

71 performed under conditions different from natural marine environments. However, the knowledge ob-

72 tained from model organisms on the molecular mechanisms underlying microbial interactions and the in-

73 creasing availability of high-quality genomes present an opportunity to map known interaction mechanisms

74 to a large set of bacterial species from various taxa. Here, we re-analyse 421 previously published genomes

75 of diverse marine bacteria that represent a significant fraction of marine microbial communities (213 gen-

76 era), providing an "atlas" of their functional metabolic capacity. The atlas includes also 52 bacteria isolated

77 from extreme marine habitats, humans and plant roots which serve as functional out-groups and represent

78 well known symbiotic bacteria. Several previous studies have aimed to characterize and cluster genomes

79 based on their predicted functional similarity, defined usually using individual genes (e.g. ${ }^{35-38}$ ) or coarse 
80 functional categories (e.g. COGs, ${ }^{37,39,40}$ )(Supplementary Table 1, Supplementary text). We chose to take a

81 trait-based approach rather than a gene-based one, which is an intermediate level of resolution between in-

82 dividual genes and coarse functions. Trait-based approaches offer a new perspective to investigating micro-

83 bial diversity with a more mechanistic understanding ${ }^{41}$ but have been used only in few specific cases to

84 highlight putative bacterial interactions (e.g., ${ }^{42}$ ). We focused on the following traits: 1 ) the metabolic capa-

85 city to synthesize or degrade specific biomolecules and to regulate such processes (KEGG modules); 2) spe-

86 cific functions related to microbial interactions, such as motility, chemotaxis and the ability to produce mo-

87 lecules such as siderophores, toxins and antibiotics. This allows to classify genomes into coherent functional

88 units, some of which recapitulate known bacterial groups with well-defined ecological roles, while others

89 refer to potential new groups. Furthermore, genetic traits can be grouped into linked trait clusters, repres-

90 enting functions that likely evolved together and may be functionally connected (i.e. participating in the

91 same process). Our approach maps the mechanisms of microbial interactions elucidated in model organ-

92 isms across bacterial diversity, suggests specific groups of bacteria likely to interact in a similar manner, and

93 identifies trait combinations that likely mediate these interactions.

95 Results and Discussion

\section{Genome functional clusters (GFCs) group genomes with similar ecology}

97 To obtain an overview on the functional capabilities of marine bacteria, we re-annotated a set of 473 high-

98 quality genomes and analysed them using a trait-based workflow, which focuses on the detection of com -

99 plete genetic traits rather than on the presence of individual genes (Supplementary Fig. 1 and Supplement-

100 ary text). Genetic traits were represented by metabolic KEGG modules, secondary metabolite pathways,

101 transporters, phytohormones and siderophores production, as well as the degradation of specific sulfur

102 metabolites. Among the identified genetic traits, those known to mediate cell-cell interactions in bacterial

103 model systems (see ${ }^{4,5,43}$ ) were flagged as "interaction traits" (e.g. production of certain vitamins, vibrioferrin

104 or a specific secretion systems; Supplementary Table 2). 
105 Based on the occurrence patterns of all traits (Fig. 1), we could cluster the genomes into 47 genome func-

106 tional clusters (GFCs; Supplementary Table 3). In each GFC, genomes encode similar genetic traits, and thus

107 GFCs are expected to be coherent in terms of functional and metabolic capacity, including the ways that the

108 grouped bacteria respond to abiotic cues and interact with other microbes. Previous genome comparison

109 approaches have identified genome clusters that match to ecologically relevant groups (e.g. ecotypes, as

110 defined for Bacillus pumilus ${ }^{36}$ and Prochlorococcus ${ }^{29}$ ) or lifestyles (e.g. oligotrophic and copiotrophic spe-

111 cies $\left.{ }^{39}\right)$. Similarly, in our analysis we found GFCs that represent group of organisms with a defined ecology

112 and life history, such as the Pelagibacterales group (GFC 2), different ecotypes of Cyanobacteria (GFCs 15

113 and 36), or Vibrio groups, characterized by different host-specificity and pathogenicity (GFCs 25 and 47)(see

114 Supplementary text). Specific GFCs were also identified for each of three groups of Gammaproteobacteria

115 (Alteromonas, Marinobacter and Pseudoalteromonas) which are typically considered as "copiotrophs", of-

116 ten associated with organic particles or phytoplankton ${ }^{44-47}$. A detailed analysis of the traits found in each of

117 the respective GFCs (Supplementary Fig. 2) suggested that Pseudoalteromonas and Alteromonas bore more

118 genetic traits involved in the resistance against antimicrobial compounds, as well as regulation for osmotic

119 and redox stresses. They also had similar vitamin B1 and siderophore transporters, which are different from

120 those encoded by Marinobacter. Marinobacter possessed several more transporters for phosphonate and

121 amino acids, as well as specific regulatory systems for adhesion (e.g. alginate and type 4 fimbriae produc-

122 tion) and chemotaxis. These patterns advocated that there might be coherent physiological and/or ecolo-

123 gical differences between these three groups. Overall, our GFC framework recapitulates previous knowledge

124 on bacterial groups with defined ecology and life history, and provides a way to delineate and characterize

125 potentially new ecological groups.

126 The correlation between functional and taxonomic classifications still represents an open question and, in

127 marine environments, recent studies have provided both supporting ${ }^{35,48}$ and disproving argumentations

128 about the strength of such correlation ${ }^{37,49}$. Therefore, we sought to understand the extent to which our re-

129 trieved GFCs overlapped with the genomes' taxonomy. In our analysis, we defined a GFC as taxonomically

130 coherent (i.e. monophyletic) when all grouped genomes belonged to the same taxon and all genomes of 
bioRxiv preprint doi: https:/doi.org/10.1101/2020.06.30179929: this version posted June 28,2021 . The copyright holder for this preprint (which was not certified by peer review) is the author/funder, who has granted bioRxiv a license to display the preprint in perpetuity. It is made available under aCC-BY-NC-ND 4.0 International license.

131 that taxon were grouped in that GFC (see Supplementary Fig. 3 and Supplementary text for more informa-

132 tion). Monophyletic GFCs imply that the taxonomic affiliation of these bacteria can predict the traits en-

133 coded in their genomes. According to this metric, 23 out of the 47 GFCs were taxonomically coherent, most

134 of them at the genus level including all Firmicutes and half of the Alpha- and Gammaproteobacteria GFCs.

135 Of the remaining 24 GFCs, 5 were polyphyletic (i.e. include genomes of different phyla) and 19 were para-

136 phyletic. Paraphyletic GFCs contained genomes of multiple taxa (differing at genus, family or even order

137 rank) whereby these taxa were also partitioned among multiple GFCs. These GFC comprised genomes of Cy-

138 anobacteria, Bacteroidota and the remaining half of the Alpha- and Gammaproteobacteria.

139 Overall, half of the detected GFCs were monophyletic and support the existence of a strong correlation

140 between taxonomy and functionality in marine bacteria, while the remaining paraphyletic GFCs highlight

141 that, in some cases, the taxonomic partitioning (based on the Genome Database Taxonomy ${ }^{50}$ ) do not com-

142 pletely reflect the functional differentiation. At the whole-community level, it has been shown that taxo-

143 nomically distinct communities exhibit similar functional profiles, which led to the suggestion that some

144 bacterial clades have similar genetic capacity, and can replace each other while maintaining unchanged the

145 community functioning ${ }^{51,52}$. The polyphyletic GFCs may group such taxonomically different but functionally

146 similar organisms, and this is supported by examples in GFCs 33 and 41 (grouping thermo- and halotolerant

147 bacteria), or GFC 17 (grouping sulfur-oxidizing and facultative anaerobe bacteria). One of the main biolo-

148 gical processes that mediates such functional "homogenisation" is horizontal gene transfer ${ }^{53,54}$ and, indeed,

149 most of the paraphyletic GFCs grouped with each other known copiotrophs or particle/host associated bac-

150 teria (e.g. Rhodobacteraceae in GFCs 9, 30 and 40, Vibrionaceae in GFCs 25 and 47, Alteromonadaceae in

151 GFCs 21 and 24, Oleiphilaceae in GFC 35, or Halomonadaceae in GFC 43; 13,18,45,55,56), whose lifestyles favour

152 events of genetic exchange (e.g. ${ }^{57}$ ). Conversely, another study suggested that this perceived similarity in

153 community function reflects only known metabolic pathways, and it is therefore possible that adding to our

154 analysis also unknown genes might separate these GFCs into monophyletic ones ${ }^{58}$. Although hypothetical

155 genes would be of no use (not informative) in a trait-based approach, we hypothesize that they could com - 
bioRxiv preprint doi: https://doi.org/10.1101/2020.06.30179929; this version posted June 28, 2021. The copyright holder for this preprint (which was not certified by peer review) is the author/funder, who has granted bioRxiv a license to display the preprint in perpetuity. It is made available under aCC-BY-NC-ND 4.0 International license.

157 phyletic GFCs.

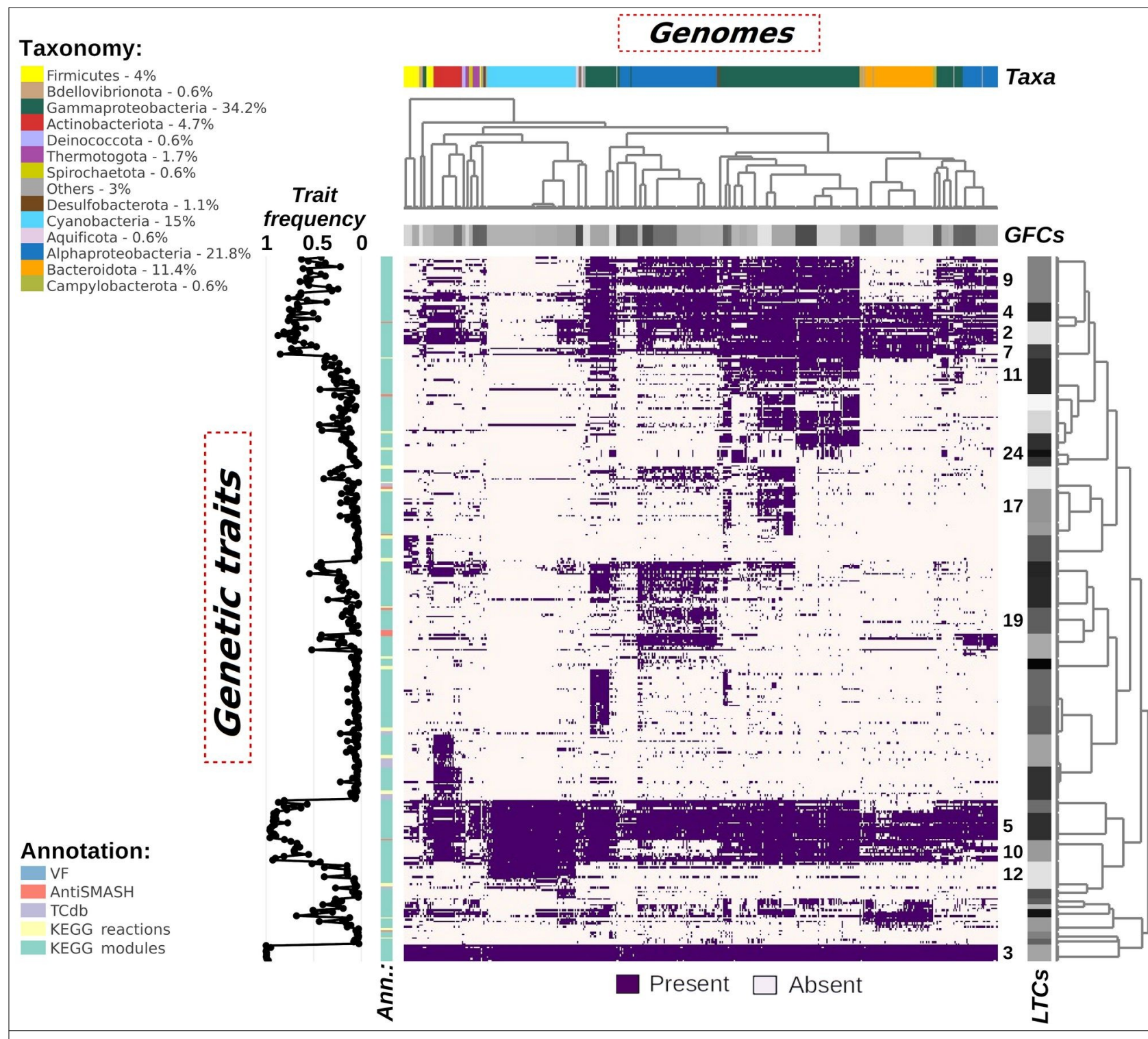

Fig. 1: Atlas of Marine Microbial Functional Traits showing presence/absence of genetic traits across all analysed genomes. Columns represent genomes grouped into genome functional clusters (GFCs) as shown by the horizontal grey bar. The horizontal colour bar represents the taxonomic affiliation of genomes (mainly phyla, with the exception of Proteobacteria that are represented at the class level). The number next to each taxon in the legend represents the percent from the total genomes analysed. Rows represent the genetic traits grouped into linked trait clusters (LTCS) as shown by the vertical grey bar. LTCs discussed 
in the text are labelled with the related number alongside the grey bar. Left-side row annotations show the frequency of each genetic trait across all tested genomes and the annotation tool (colour coded bar) with which they have been identified. Both dendrograms are computed using the aggExCluster function ( $r$ package apcluster) that generates hierarchal clustering from an affinity propagation result. An interactive version of this figure is available as Supplementary file 1.

\section{GFCs are ecologically-relevant entities in natural communities}

To what extent do the GFCs represent the diversity of natural communities, or display dynamics expected from ecological units in the oceans? To test this, we mapped the 16S rDNA reads from a natural coastal community that was sampled at high temporal frequency ${ }^{59}$ to the GFCs (Supplementary text and Supplementary Fig 4). Firstly, a significant fraction of the natural community was represented with high fidelity in the GFCs (mean $22.9 \%$ of the $16 \mathrm{~S}$ rDNA reads, range 12.7-44.3\%). Thus, despite the inherent bias derived from using only high-quality, closed genomes available (mainly) from cultured bacteria (legend of Figure 1), the GFCs represented a significant fraction of bacterial diversity. Similar results were obtained with an openocean community from the Eastern Mediterranean sampled each season for 3 years ${ }^{60}$ (mean $13.9 \%$ of the $16 \mathrm{~S}$ rDNA reads, range $0.5-60.0 \%)$, where the GFCs represented a significantly higher fraction of the microbial community on particles $>11 \mu \mathrm{m}$ compared to free-living bacteria (5-0.22 $\mu \mathrm{m}$; Supplementary Fig. 5).

171 Secondly, using a temporal deconvolution analysis of the coastal site ${ }^{59}$ we found that individual 165 phylo-

172 types belonging to the same GFC displayed significantly more synchronous temporal trends ( $p$-value < 173 0.001) than phylotypes belonging to different GFCs (Supplementary text and Supplementary Fig. 6). Assum174 ing that similar temporal trends suggest similar ecological niches, these results suggest that (at least some 175 of) the GFCs represent bona-fide ecological units. 


\section{Specific GFCs are enriched in "interaction traits"}

178 We next focused on selected traits potentially involved in microbial interactions - vitamin exchange,

179 siderophore and phytohormone production and antibiosis - asking whether we could observe patterns in

180 their distribution across the genome dataset. As shown in Figure 2, these traits are not equally distributed

181 among the GFCs - rather, some GFCs were significantly enriched in "interaction traits" (Supplementary Fig.

$1827 a-b)$. While the number of interaction traits depended to some extent on genome size, as expected from

183 previous studies ${ }^{61,62}$, Gammaproteobacteria and several Alphaproteobacteria encoded more interaction

184 traits than expected by their genome size, while Bacteroidota encoded fewer (Supplementary Fig. 7c-d).

185 Overall, GFCs grouping genomes of typical host- or particle-associated bacteria, such as of Alpha- and

186 Gammaproteobacteria ${ }^{56}$, are predicted to bear almost the full combination of these traits to sense (chemo-

187 taxis, quorum sensing), reach (motility and adhesion) and fight (production/resistance towards antimicro-

188 bial compounds, secretion systems) for a targeted hotspot. Contrary, some ubiquitous copiotrophs (e.g.

189 Bacteroidota) ${ }^{56}$ and known free-living taxa (e.g. pico-Cyanobacteria and Pelagibacterales) ${ }^{29,61}$ possess only a

190 scarce and scattered equipment of such traits. Below, we describe in more detail some of the main observa-

191 tions on the distribution of interaction traits across diversity. 
bioRxiv preprint doi: https://doi.org/10.1101/2020.06.30.179929; this version posted June 28, 2021. The copyright holder for this preprint (which was not certified by peer review) is the author/funder, who has granted bioRxiv a license to display the preprint in perpetuity. It is made available under aCC-BY-NC-ND 4.0 International license.

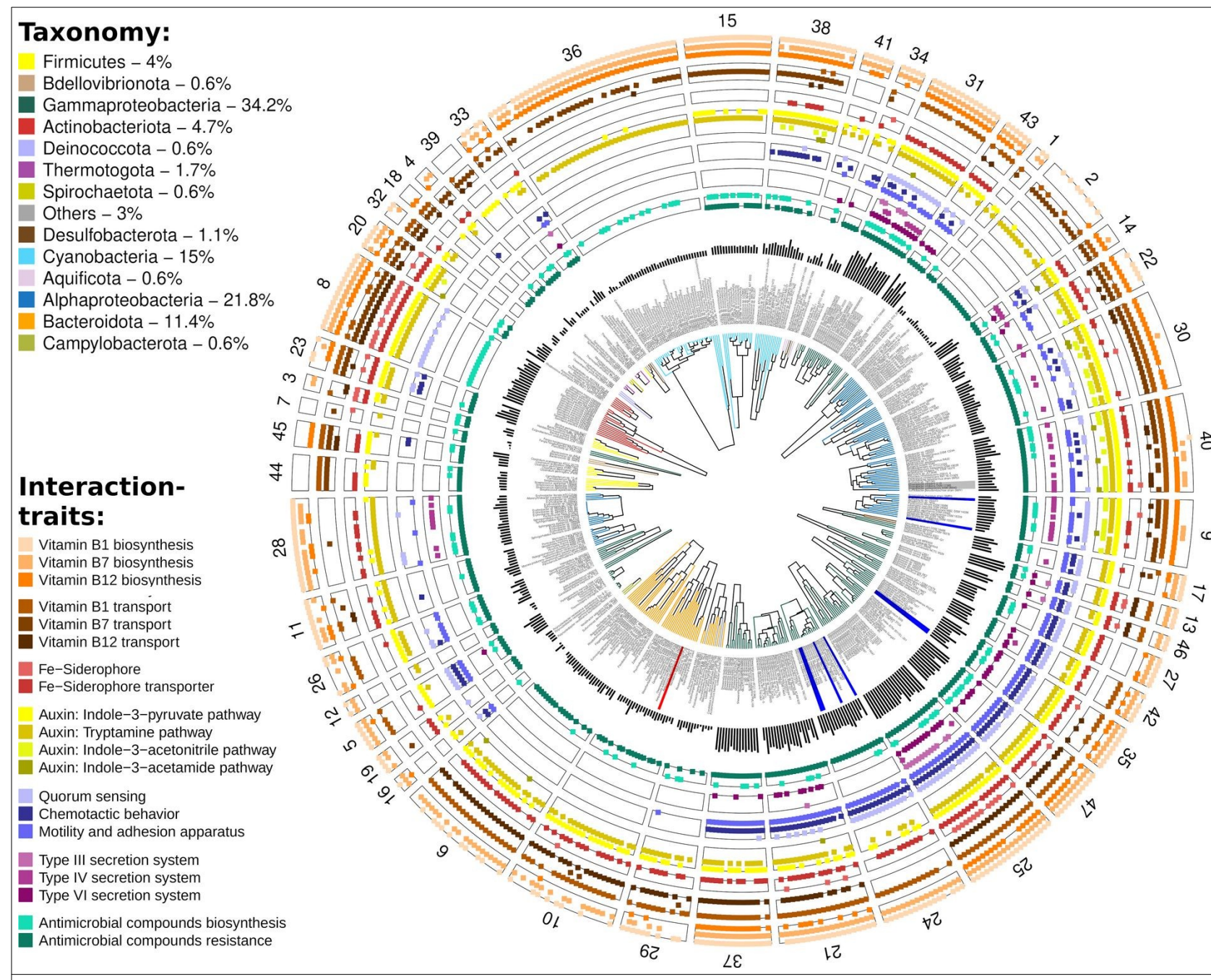

Fig. 2: Distribution across genome functional clusters (GFCs) of interaction traits known to mediate cell-cell interactions in bacterial model systems. Each slice shows the interaction traits present in a GFC and, as dendrogram, the functional similarity of genetic traits between the grouped genomes (hierarchical clustering of r-correlation matrix with complete agglomeration algorithm). The dark bars show the number of in teraction traits annotated in each genome. Genomes belonging to model bacteria used to discover some of these traits are highlighted in blue if the interaction was positive (e.g. enhancing phytoplankton growth), in red if it was negative (e.g. kill the host) or in grey if the interaction shifted from positive to negative.

\section{Many bacteria need "to shop" for their vitamins}

195 Vitamins $B_{1}, B_{7}$ and $B_{12}$ are essential cofactors for microbes. Some microorganisms (including abundant 196 phytoplankton) are auxotrophic for these vitamins and need to obtain them from co-occurring bacteria ${ }^{63,64}$. 
bioRxiv preprint doi: https:/doi.org/10.1101/2020.06.30179929: this version posted June 28,2021 . The copyright holder for this preprint (which was not certified by peer review) is the author/funder, who has granted bioRxiv a license to display the preprint in perpetuity. It is made available under aCC-BY-NC-ND 4.0 International license.

197 Vitamins are found at low concentrations in aquatic ecosystems ${ }^{65,66}$ and their supply can limit biogeochem-

198 ical cycles, e.g. through limiting primary productivity in the Southern Ocean ${ }^{67}$. Less than half of all the gen-

199 omes in our dataset were predicted to produce all three vitamins ( $\sim 39 \%$, including all pico-Cyanobacteria,

200 Actinobacteriota and many Gammaproteobacteria; Fig. 3a). Of the rest, 29\% synthesized at least two B vit-

201 amins (e.g. some Alphaproteobacteria, Bacteroidota and the rest of Gammaproteobacteria, which could

202 produce vitamin $B_{1}$ and $B_{7}$ ) and $\sim 23 \%$ could produce only one type of $B$ vitamin (or $~ 9 \%$ none at all). This

203 suggests that there is a major "market" for B vitamins, and indeed almost all genomes ( 83\%) encoded

204 transporters for at least one vitamin.

205 A more detailed analysis of the genomes suggested that marine bacteria could be divided into three main groups based on their predicted strategy for B vitamins acquisition: (1) "consumers", which lacked the biosynthetic genes but harboured the vitamin transporters (we assumed transporters were for uptake, see Supplementary text for details on transporters' directionality); (2) "independents", which encoded the biosynthetic pathways but not the relevant transporters; (3) "flexibles", which encoded both the biosynthetic pathways and transporters for a specific vitamin. Bacteria possessing the latter strategy can potentially switch from being consumers to independent or vice-versa, according to what is more efficient given the surrounding conditions (e.g. availability of extracellular vitamins). The proportion of these three groups changed with the B vitamin studied and the taxonomy of the genomes (Fig. 3b). Very few genomes were

214 flexibles for all three vitamins ( $2 \%)$, and these were mostly Actinobacteriota (Fig. 3c). There were almost equal proportions of flexibles and independents for vitamin $B_{1}$ (Gammaproteobacteria and Cyanobacteria, respectively), whereas the most common bacterial strategies for vitamin $B_{7}$ and $B_{12}$ were independent (Fig.

217 3b). Many different combinations of synthesis and uptake of the three vitamins were represented in the 218 genomes (51 out of 64 possible combinations, Fig. 3c and Supplementary Fig 8a), several being enriched in 219 specific GFCs (Supplementary Fig 9 and Supplementary text) and, notably, most strategies required the exo220 genous uptake of at least one vitamin. While the perceived lack of biosynthetic capacity could be due to the 221 utilization of precursors or to gaps in the pathway annotations (see Supplementary Fig 10 and Supplement222 ary text), we speculate that this could be a potential manifestation of the "Black Queen" hypothesis, which 
bioRxiv preprint doi: https://doi org/10.1101/2020.06 30 179929; this version posted June 28,2021 . The copyright holder for this preprint (which was not certified by peer review) is the author/funder, who has granted bioRxiv a license to display the preprint in perpetuity. It is made available under aCC-BY-NC-ND 4.0 International license.

223 stipulates that bacteria "outsource" critical functions to the surrounding community, enabling a reduction of

224 their metabolic cost ${ }^{68}$. In our dataset, the highest fraction of B-vitamin consumers, and hence putative

225 auxotrophs, was observed for vitamin $B_{1}$, followed by $B_{12}$ and $B_{7}$. This order, however, does not reflect the

226 metabolic costs of producing such vitamins, as $B_{12}$ would be the most "expensive" with about 20 genes in-

227 volved ${ }^{69}$, whereas only 4 genes are required to synthesize $\mathrm{B}_{7}{ }^{63}$ and 5 genes for $\mathrm{B}_{1}{ }^{70,71}$. Therefore, we hypo-

228 thesized that vitamin $B_{1}$ supplies might be more stable or frequent (e.g. as a result of higher export or lysis

229 of producing bacteria) than that of vitamin $B_{12}$. Nevertheless, very few organisms were predicted to be

230 auxotrophic for all three vitamins, suggesting that completely relying on exogenous sources for vitamins

231 represents a risky strategy in marine pelagic environments. Taken together, these data provide a compre-

232 hensive overview of the market for B vitamins in marine environments by defining specific roles (e.g. con-

233 sumer, independent, flexible/source) and identifying which bacteria (taxon and GFC) fulfil each role. 
bioRxiv preprint doi: https://doi.org/10.1101/2020.06.30179929: this version posted June 28,2021 . The copyright holder for this preprint (which was not certified by peer review) is the author/funder, who has granted bioRxiv a license to display the preprint in perpetuity. It is made available under aCC-BY-NC-ND 4.0 International license.

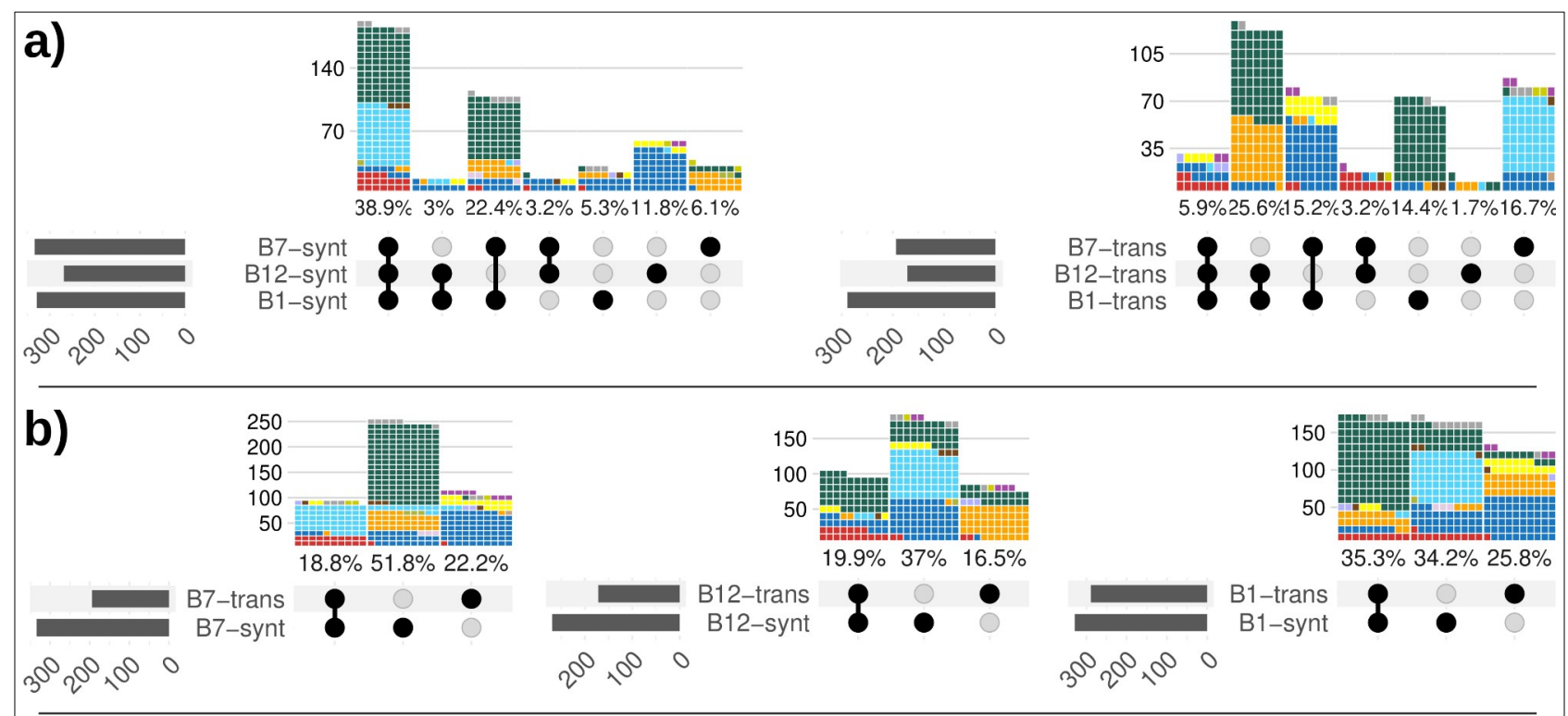

\section{c)}
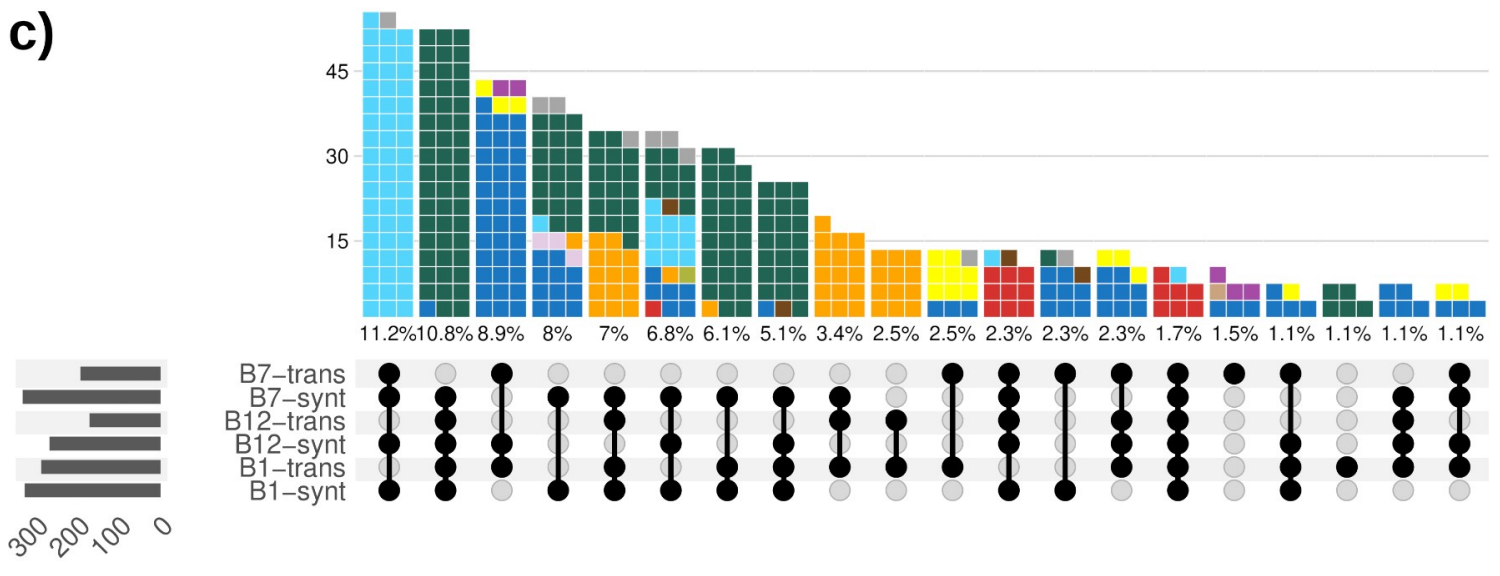

\section{Taxonomy:}

Firmicutes - 4\%

Bdellovibrionota - $0.6 \%$

Gammaproteobacteria - 34.2\%

Actinobacteriota - 4.7\%

Deinococcota - 0.6\%
Thermotogota - 1.7\% Spirochaetota - $0.6 \%$ Others - 3\%

Desulfobacterota - 1.1\% Cyanobacteria - 15\%

Fig. 3: Plots of intersecting sets showing different genomic configurations of traits for the biosynthesis and transport of vitamins $B_{1}, B_{12}$, and $B_{7}$ : (a) capabilities to produce or transport these vitamins, (b) different configurations to either produce and/or transport each of these vitamins, and (c) the most abundant con figurations to produce and/or transport these vitamins across genomes; the remaining combinations are shown in Supplementary Fig. 8a. Overall, the left bar chart indicates the total number of genomes for each trait, the dark connected dots indicate the different configurations of traits and the waffle bar chart indicates the number (and percentage) of genomes provided with such a configuration; each piece of a waffle bar represents a genome and it is coloured according to the taxon. 


\section{Production of siderophores and phytohormones - key mechanisms of 237 synergistic microbial interactions}

238 The production and exchange of "common goods" such as siderophores ${ }^{72}$, as well as of specific phytohormones like auxin ${ }^{73}$ represent traits that may mediate synergistic microbial interactions. As shown in Fig. 2, approximately $10 \%$ of the genomes have the capacity to produce siderophores (mainly Actinobacteriota and Gammaproteobacteria), while almost half of the genomes, from multiple taxa, encoded siderophore

242 transporters (45\% of the genomes). The occurrence of siderophores biosynthetic traits was partially follow-

243 ing the GFC clustering (e.g. GFC 8, Actinobacteriota and GFC 25, Gammaproteobacteria) and partially

244 scattered across single genomes in different taxa. In contrast, the distribution of the transporters mainly fol-

245 lowed the GFC grouping (Fig. 2). Furthermore, microorganisms can utilize siderophore-bound iron also

246 without the need for siderophore transporters, e.g. using ferric reductases located on the plasma mem-

247 brane ${ }^{74}$ or via direct endocytosis ${ }^{75}$. In this regard, $5 \%$ of the genomes encoded the capacity to produce vi-

248 brioferrin (Supplementary Fig. 11), which is available to a wide range of organisms upon photolysis ${ }^{21}$. Field

249 studies revealed that siderophore biosynthesis is widespread in the ocean ${ }^{76}$, and that bacteria producing

250 e.g. vibrioferrin can represent a relevant percentage of the total bacterial communities ${ }^{77}$. Thus,

251 siderophores can be considered as "keystone molecules" ( $\left.\operatorname{sensu}^{78}\right)$, produced by a limited subset of organ-

252 isms but utilizable by a wide range of bacteria ${ }^{79-81}$.

253 Several recent studies have shown that bacteria can influence the growth of phytoplankton through the

254 production of phytohormones ${ }^{13,18,24}$, and indeed the auxin hormone indole-3-acetic acid (IAA) has been

255 identified in natural marine samples ${ }^{13}$. Nearly all genomes ( 92\%) in our dataset are predicted to produce

256 IAA. Four pathways for the production of IAA were identified, with some organisms encoding more than

257 one pathway. The tryptamine pathway was the most common one and was present in nearly all GFCs com-

258 prising genomes of Alphaproteobacteria, Gammaproteobacteria, Cyanobacteria and Actinobacteriota (Fig.

259 2). The indole-3-pyruvate pathway was the second most common with an almost identical distribution to

260 the tryptamine pathway (missing in GFCs 36 and 15, pico-Cyanobacteria, and 28, Alphaproteobacteria),

261 whereas the last two pathways were rarer ( $<10 \%$ of genomes) and limited to Alphaproteobacteria (indole-3- 
acetonitrile) and some genomes of Cyanobacteria and Actinobacteriota (indole-3-acetamide). It is tempting

to speculate that the widespread distribution of the capacity to produce IAA, and the diversity of biosyn-

thetic pathways, suggest that many heterotrophic bacteria can directly increase phytoplankton growth

through specific signalling (e.g. ${ }^{13,18}$ ). However, all pathways for IAA production are tightly intertwined with

266 the metabolism of tryptophan, either involved in tryptophan catabolism (to cleave the amino group for nitrogen metabolism) or as a "release valve" to avoid the accumulation of toxic intermediates (e.g. $\alpha$-keto acid indolepyruvate and indoleacetaldehyde). Additionally, IAA can be catabolized as a carbon source for

whereas the indole-3-acetonitrile and indole-3-acetamide pathways could be responsible for the production of IAA involved in phytoplankton-bacteria interactions. This hypothesis is supported by the presence of the latter traits in GFCs 9 and 40 that group model organisms known to interact through auxin with phytoplankton (Fig. 2) $13,18,24$, and by the fact that genes specifically related to these two pathways were found to be upregulated in one of those studies ${ }^{13}$.

\section{Traits underlying potential antagonistic interactions}

278 Experimental measurements of interactions among marine bacteria suggest that antagonism is common

279 ( $>50 \%$ of the tested isolates $)^{32,34}$, but in most cases the mechanisms behind antagonistic interactions are un-

280 clear. Antimicrobial compounds may underlie many antagonistic interactions in marine environments (e.g.

$\left.281^{83-85}\right)$, and indeed genes encoding for the production of such compounds were found in several bacteria in

282 our dataset (Supplementary Tables 5 and 6). Interestingly, antimicrobial compounds were predicted to be

283 produced in $~ 30 \%$ of genomes (inner ring in Fig. 2), including also GFCs poor in other interaction traits. The

284 most abundant traits across GFCs were bacteriocin and betalactone production ${ }^{86,87}$ (Supplementary Fig. 12).

285 Genes involved in the resistance to antimicrobial compounds were also relatively common (78\% of gen-

286 omes; Fig. 2), however, along with "specific" resistance traits (e.g., efflux pumps specific for antibiotics), we 
noticed many KEGG modules that were annotated as "antimicrobial compounds resistance" but were also

288 involved in other cellular functions (e.g. cell division, protein quality control and transport of other com-

289 pounds; Supplementary Table 5) ${ }^{88,89}$. All GFCs which grouped genomes of Cyanobacteria, Actinobacteriota,

290 and Bacteroidota possessed only these "generic" resistance traits (Supplementary Fig. 12), suggesting that

291 such clades are less efficient in resisting microbial "chemical warfare". In support of this hypothesis, some

292 Cyanobacteria strains are indeed used as markers for antibiotic contamination because of their sensitivity

293 (e.g., references ${ }^{90,91}$ ), and Bacteroidota are often inhibited when co-cultured with other bacteria that ex-

294 press antagonistic behaviour ${ }^{32,34}$. Overall, these genome-based predictions are in agreement with previous

295 experimental results ${ }^{32,34}$, which suggested that Alpha- and Gammaproteobacteria commonly inhibited other

296 bacteria, whereas Bacteroidota had a low inhibitory capacity and were the most sensitive to inhibition by

297 other bacteria.

298 Antimicrobial compounds or toxins often need to be delivered into the target organism, e.g. using type IV or

299 type VI secretion systems (T4SS and T6SS, respectively). Approximately $24 \%$ of the strains encoded T4SS or

300 T6SS, and these were found primarily in GFCs containing Alpha- and Gammaproteobacteria (Fig. 2). The two

301 secretion systems had different distributions among the GFCs, with only GFC 25 and 31 (comprising Vibrio

302 and Burkholderia, genera of Gammaproteobacteria) bearing both systems. The T4SS system can perform

303 multiple roles, including conjugation, DNA exchange and toxin delivery in bacteria-bacteria or bacteria-euk-

304 aryote interactions ${ }^{92}$. T4SSs were detected more frequently in Alphaproteobacteria (5 out of 8 GFCs). To

305 date, T6SSs are known to be involved only in antagonistic interactions, including among marine bacteria ${ }^{93}$,

306 suggesting that the presence of this trait is a high-confidence predictor of the ability to directly inhibit other

307 cells ( ${ }^{94}$ and references therein). In our dataset, T6SSs occurred almost exclusively in GFCs comprising

308 Gammaproteobacteria, specifically in Marinobacter and Vibrio, suggesting a strong capacity for contact-me-

309 diated antagonistic interactions in these taxa. Type III secretion systems (T3SS), which deliver effector mo-

310 lecules that maintain the bacterial association with the host ${ }^{95}$, were found only in a few genomes as the $\mathrm{Vi}$ -

311 brio clustered in GFC 25. This GFC grouped known zooplanktonic hosts ${ }^{55}$, suggesting a more specific role for

312 T3SS in metazoan host-microbe interactions. 


\section{Linked trait clusters (LTCs) delineate functional connectivity between in- 315 dividual interaction traits}

316 While individual traits may be important in determining the outcome of microbial interactions, such interac-

317 tions are often highly complex, requiring multiple traits such as motility, signalling and metabolic interac-

318 tions to operate together (e.g. ${ }^{13,18,20,23,24}$ ). If these interaction mechanisms are evolutionarily conserved,

319 traits that are functioning together to mediate such interactions should co-evolve, meaning that selection

320 would favour maintaining all relevant traits in the same genome ${ }^{96,97}$. To identify cases of co-evolving traits,

321 we used linkage disequilibrium analysis and clustered traits which were found together more often than ex-

322 pected by chance (adjusted p-value $<0.05$ ) into Linked Trait Clusters (LTCs; Figure 1, Supplementary Table 7

323 and Supplementary Fig 13). For example, LTC 10 includes pathways for assimilatory sulfate reduction, siro-

324 heme and heme biosynthesis, as well as vitamins $B_{1}$ and $B_{7}$ biosynthesis. These traits appeared together

325 more often than random pairs of traits (mean $r$ within this LTC is 0.38 , compared to 0.09 among all traits;

326 Supplementary Fig. 13b) and they are also functionally linked. In fact, siroheme is a prosthetic group for as-

327 similatory sulfite reductases ${ }^{98,99}$ and, in sulfate-reducing bacteria, siroheme can be "hijacked" for the bio-

328 synthesis of heme ${ }^{100}$. Finally, once reduced, sulphur can be incorporated into essential molecules such as

329 amino acids (methionine and cysteine) and membrane lipids, as well as into vitamins $\mathrm{B}_{1}$ and $\mathrm{B}_{7}{ }^{101}$.

330 We focus first on LTCs grouping traits not directly involved in interactions. Two LTCs, 3 and 5 (mean r of 0.30

331 and 0.35 ), occurred in nearly all genomes (>93\%; Fig. 1) and, as expected, they linked traits which mediate

332 for core metabolic functions, common to any cell. These include biosynthesis of nucleotide (DNA and RNA)

333 and amino acids, as well as core metabolic pathways (glycolysis, pentose phosphate pathway and the first

334 three reactions of the TCA cycle). In contrast, other LTCs (i.e. 2, 4 and 7) highlighted cases in which major

335 metabolic pathways such as the TCA cycle or pathways for the cell wall assembly were missing in specific

336 bacterial clades. These absence-patterns were consistent with previous studies (see Supplementary Text for 
detailed description). The LTC concept can, therefore, be used to identify traits that may function together, providing hypotheses as to new modes of interaction that can be tested experimentally.

339 Analysis of LTCs which include interaction traits such as secretion systems suggested that these are linked

340 also to traits encoding for chemotaxis, motility and adhesion, a typical set of traits a bacterium would need

341 to locate, reach and settle on an organic matter particle or eukaryotic hosts (phytoplankton, zooplankton,

342 fish). Moreover, other genetic traits (e.g. metabolic or regulatory) were linked within these LTCs and they

343 may also be involved in microbial interactions (Fig. 4). For example, LTC 11 (mean $r=0.40$ ) included, in addi-

344 tion to T6SS, traits for adhesion, a flagellar regulatory system, quorum sensing (controlling for swarming and

345 biofilm formation), chemotaxis and a nitrogen transporter with the regulation system. The same LTC also

346 encoded for the biosynthesis of ubiquinone, vitamins $B_{6}$ (pyridoxal) and $B_{7}$, and for two regulatory systems

347 (BarA-UvrY, RstB-RstA), which are known to regulate virulence, metabolism, biofilm formation, stress resist-

348 ance, quorum sensing and secretion systems (see ${ }^{102,103}$ ). This LTC was common in the GFCs grouping

349 Gammaproteobacteria such as Pseudoalteromonas (GFC 21) Alteromonas (GFC 24), Marinobacter (GFC 35),

350 Shewanella (GFC 37) and Vibrio (GFCs 25 and 47; Supplementary Tables 3 and 7). All of these organisms are

351 known as particle and phytoplankton associated bacteria (e.g. ${ }^{44-47,56}$ ), and in such micro-environments they

352 can engage in microbiome interactions using these linked traits (i.e. biosynthesis of B vitamins, quorum

353 sensing and T6SS; $\left.{ }^{93,104}\right)$. Interestingly, the other two secretion systems, T4SS and T3SS, were also linked with

354 the regulation of nitrogen metabolism and with vitamin $B_{7}$ or $B_{12}$ transport as part of LTC 25 and LTC 17, re-

355 spectively. We propose that this provides further support for a putative functional link between microbial

356 interactions (injection of effector molecules), nitrogen and vitamin metabolism.

357 Notably, LTC 17 (which encodes the T3SS; mean $r=0.47$ ) included also amino acid and sugar transporters,

358 and two regulation systems (UhpB-UhpA, CitA-CitB). The UhpB-UhpA genes control the motility and coloniz-

359 ation of fish pathogens ${ }^{105}$ and, not surprisingly, the LTC was found in GFCs 46 and 47 which included known

360 pathogenic bacteria (grouping Aeromonas and V. natriegensis genomes; Supplementary Tables 3 and 7)

$361{ }^{106,107}$. LTC 17 was also found in GFCs that grouped non-pathogenic but still host associated taxa (GFC 25,

362 which includes V. alginolyticus and GFC 13 grouping Enterobacteriaceae) ${ }^{108}$, supporting the role of this LTC 
363 (as well as of the T3SS it encodes) in interactions with eukaryotic hosts. Moreover, CitA-CitB regulation sys-

364 tem controls the citrate metabolism in response to changes of amino acid concentration or $\mathrm{pH}^{109}$. We spec-

365 ulate that the link between microbial interaction traits, citrate metabolism and protein and amino acid

366 transporters within LTC 17 may be relevant for a host-associated bacteria during the dispersal stage (lower

367 amino acid concentration and change in $\mathrm{pH}$ changes).

368 Finally, the analysis of LTC 19 (mean $r=0.34$ ) lent further support for the hypothesis that some IAA produc-

369 tion pathways are involved in phytoplankton-bacteria interactions and not just in the tryptophan catabolism

370 (see above). This LTC included the indole-3-acetonitrile and indole-3-acetamide pathways, along with other

371 key microbial-phytoplankton interaction traits such as quorum sensing ${ }^{24,110}$ and taurine degradation ${ }^{13,16}$.

372 Other linked genetic traits hint to additional molecular mechanisms: the manganese/iron transporter sug-

373 gests a micronutrient-dependent response, the transport of capsular polysaccharide may be involved in res-

374 istance to host defence and pathogenicity ${ }^{111}$, and the biosynthesis of putrescine can stimulate phytoplank-

375 ton growth, productivity and stress tolerance, as shown previously in plants ${ }^{112}$. Moreover, the LTC was

376 found complete in GFCs 9, 30 and 40 (Supplementary Table 7) which grouped genomes of bacteria known

377 to interact via IAA with phytoplankton (e.g. Dinoroseobacter, Sulfitobacter and Phaeobacter) ${ }^{13,18,24,113}$. We

378 propose that possessing this LTC indicates that the relevant bacterium is capable of affecting the growth of 379 phytoplankton through a combination of specific hormone signalling pathways and metabolic interactions. 


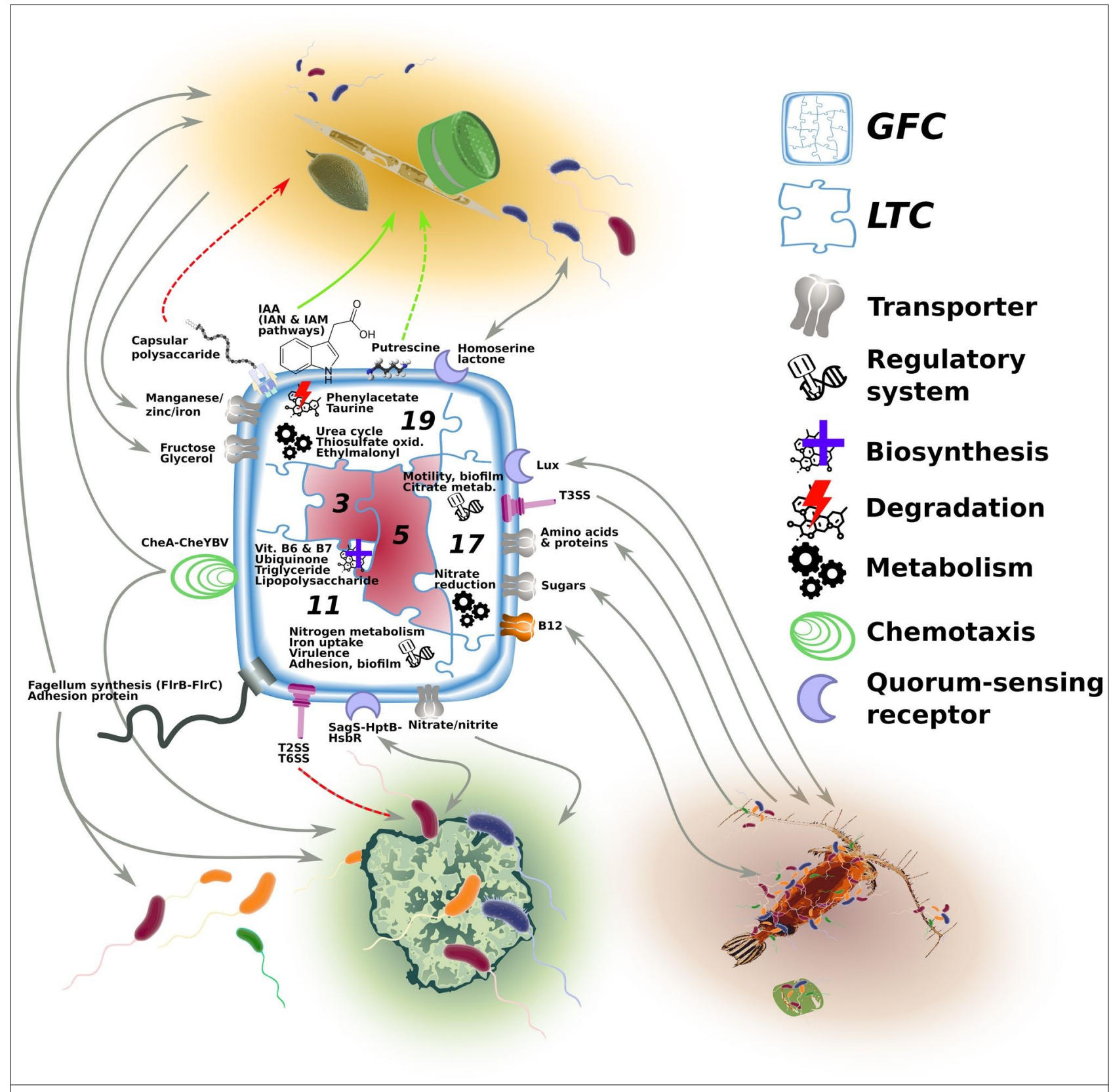

Fig. 4: Conceptual representation of the predicted interaction dynamics for an hypothetical bacterium analysed with our trait-based approach. The bacterium is assigned to a GFC, visualized here as a jigsaw puzzle. Every puzzle piece represents one of the linked trait clusters (LTCs) possessed in that GFC. LTCs 3 and 5 (marked in red) are the core LTCs and they are present in any GFC. In this example, the GFC also possess the ancillary LTCS 11, 17 and 19. Each of these ancillary LTC predicts specific interaction types with bacteria, organic matter particles, phytoplankton or other eukaryotic hosts (e.g. fish, zooplankton). Green arrows indicate traits with positive effects (e.g. enhancing growth), grey arrows traits mediating metabolites/chemical exchange, movement or attachment, and red arrows traits with negative effects (e.g. 
pathogenicity). A solid arrow is used when the mediated mechanism has already been described in literature, while a dashed arrow indicates a potential new mechanism.

\section{Summary and outlook}

383 We present a framework that extrapolates from studies of specific model organisms to predict the interac-

384 tion potential of other bacteria based on the traits encoded in their genomes. By focusing on biologically

385 relevant traits (including specific interaction traits), we reduced a highly complex genomic dataset to a tract-

386 able matrix of organisms by functions. By organizing the ensuing genomic information into GFCs, we further

387 simplified the interpretation of complex genomic datasets, while at the same time highlighting the non-

388 trivial grouping of organisms by phenotypic traits, sometimes irrespective of taxonomic boundaries. The

389 LTCs provided evidence for the functional and evolutionary linkage between traits, raising hypotheses as to

390 how these traits act together in the context of complex processes such as microbial interactions. This ap-

391 proach can be easily scaled to different ecosystems (e.g. freshwater or terrestrial) and expanded to include

392 information from additional data sources (e.g. metabolomics or high-throughput functional assays).

393 Applying this approach to a wide diversity of bacterial taxa, we showed that marine bacteria encode differ -

394 ent configurations of interaction traits and can, therefore, engage in different interaction types. Known

395 particle associated taxa of Alpha- and Gammaproteobacteria possessed the full set of traits to interact with

396 particles and living hosts, while Bacteroidota, a known ubiquitous copiotroph taxon, did not have this capa-

397 city. Actinobacteriota and Cyanobacteria represented potential sources for $B_{7}$ in the $B$ vitamin market, while

398 most Alphaproteobacteria appeared as obligate customers. We suggest that siderophores, and vibrioferrin

399 in particular, are keystone molecules being produced by only a few bacteria (Actinobacteriota and

400 Gammaproteobacteria) but affecting a much larger diversity of potential users, in agreement with the Black

401 Queen Hypothesis ${ }^{68}$. Finally, the production of IAA might be more common than expected, and in some

402 cases (e.g. GFCs 9, 30 and 40 encoding LTC 19) this may be linked with other traits involved in phytoplank-

403 ton-bacteria interactions. 
404 As with any bioinformatic approach, also our workflow aimed to identifying functional traits on genome se-

405 quences, has inherent limitations. Firstly, on average, only $63 \%$ of genes were functionally annotated across

406 genomes (range $\sim 40-80 \%$ ), with the remaining genes either annotated as hypothetical or not annotated at

407 all. This is a strong reminder of the limitations of current genomic and metabolic knowledge. Secondly, only

408 a fraction of the natural microbial diversity was represented by high-quality sequenced genomes, leading to

409 a bias in the representation of different clades in the analysed dataset (Figure 1). While the analysed gen-

410 omes did represent a significant fraction of natural diversity (Supplementary Fig.s 4 and 5), a future work,

411 both culture dependent and independent, is needed to close these gaps and obtain an unbiased view of the

412 traits encoded by marine microorganisms. Finally, the GFC and LTC concepts are both statistical in nature,

413 representing the probability of bacteria having similar functional capacity, and of traits being functionally

414 and/or evolutionarily linked. In support of the GFC concept, a study of marine Vibrionaceae suggested that

415 ecologically-cohesive unit (similar to GFCs) are likely to interact in a similar way ${ }^{30}$. However, some interac-

416 tion phenotypes, such as the ability to inhibit multiple target bacteria ("super-killers"), are not phylogenetic-

417 ally conserved ${ }^{30,114}$. Experimental studies using both established and new model systems across multiple

418 scales of diversity (e.g. between and within GFCs) are needed to test the GFC framework, whereas genetic

419 manipulation of linked traits to test their effect on microbial interactions will be required to determine to

420 what extent traits within LTCs are functionally linked. Nevertheless, GFCs and LTCs describe how putative in -

421 teraction traits vary across microbial diversity, and thus can be used to quantify how the fraction of natural

422 communities potentially "ready to interact" changes over space and time. In turn, this should help to elucid-

423 ate fundamental rules that govern community dynamics and assembly in the oceans, and the roles played

424 by microbial interactions will in global ecosystem-level processes and biogeochemistry. 


\section{Materials and Methods}

\section{Genome selection}

429 A dataset of complete and high-quality draft genomes of marine bacteria was compiled performing an ex-

430 tensive research on metadata available from NCBI (http://www.ncbi.nlm.nih.gov/genome), JGI (https://

431 img.jgi.doe.gov/cgi-bin/m/main.cgi?section=FindGenomes\&page=genomeSearch), and MegX (https://

432 mb3is.megx.net/browse/genomes) websites. Although the focus of the analysis was on bacteria inhabiting

433 the marine pelagic environment, some genomes from organisms isolated in extreme marine environments

434 (i.e. thermal vents, saline and hypersaline environments, estuaries) and sediment, as well as from human

435 and plant symbionts (Sinorhizobium and Mesorhizobium) were kept for comparison. The final list of 473

436 genomes includes all of the genomes that, using CheckM ${ }^{115}$, were defined "closed" (i.e. each DNA molecule,

437 such as chromosome and plasmids, was represented as a single sequence in the fasta file) or high-quality

438 draft genomes ( $>90 \%$ of completeness, $<10 \%$ of contaminations, $>18$ tRNA genes and all 3 rDNAs present)

$439{ }^{116}$. The final dataset included 473 complete genomes with 117 closed genomes and with $>81 \%$ genomes

440 that were $>99 \%$ complete. Of these 473 genomes, 421 were isolated in marine pelagic and coastal zones, 34

441 in extreme environments (e.g. salt marsh or hydrothermal vent), 6 in marine sediment and, of the remain-

442 ing, 8 were human associated and 4 plant roots associated (Supplementary Table 3).

\section{Genome annotation}

444 Genome taxonomic classification was obtained using the protein phylogeny workflow implemented in

445 GTDB-tk v1.4.0 ${ }^{50}$ with the command classify_wf (standard settings), and all retrieved genomes were func-

446 tionally re-annotated using a standardized pipeline. In brief, gene calling and first raw annotation steps were

447 performed with Prokka v1.14.5 (standard settings and '--rnammer' for rRNA prediction) ${ }^{117}$. The amino acid

448 sequences translated from the identified coding DNA sequences of each genome were annotated against

449 pre-computed hidden Markov model profiles of KEGG Ortholog (KEGG database v94.0) using kofamscan

$450 \mathrm{v} 1.2 .0$ (standard settings) ${ }^{118}$. Additional targeted analyses were performed to annotate secondary metabol-

451 ites, phytohormones, specific transporters and utilization of sulfur-metabolites. The genbank files generated 
452 by Prokka were submitted to a local version of Anti-SMASH v5.1.2 (--clusterblast --subclusterblast --known-

453 clusterblast --smcogs --inclusive --borderpredict --full-hmmer --asf -tta), which generated a list of predicted

454 secondary metabolite biosynthesis gene clusters ${ }^{119}$. Different pathways for the biosynthesis of the phyto-

455 hormone indole-3-acetic acid (IAA) were manually identified by annotating (blastp v2.9.0 best hit, e-value

$456<1 \mathrm{e}-5$ and bit score $>60^{120}$ ) the translated amino acid sequences against the KEGG orthologies required to

457 generate IAA from trypthopan in the KEGG map01070 (Supplementary Table 8; Supplementary file 3). Trans-

458 lated amino acid sequences were also used as input for a GBlast search (BioV suite; standard settings) ${ }^{121}$ to

459 identify trans-membrane proteins mediating the transport of B vitamins and siderophores(Supplementary

460 Table 4). For downstream analysis, only annotations with a trans-membrane alpha-helical overlap score $>1$ and a blast e-value $<1 \mathrm{e}-6$ were retained. Production and transport of photoactive siderophores (i.e. vibrioferrin) ${ }^{21}$ were identified with functional annotations from the most similar (BLAST best hit) sequences. The predicted protein sequences were blasted (blastp v2.9.0; e-value $<1 e-5$ and amino acid similarity $>30 \%$ ) ${ }^{122}$ against a reference dataset assembled using all available sequences of related genes (pvsABCDE and pvuBCDE operons) ${ }^{123}$ available in UniProt (Supplementary Table 9 and Supplementary file 4). The same approach was carried out to annotate the dimethylsulfoniopropionate (DMSP) degradation pathways of demetilation and cleavage blasting (e-value $<1 e-70)$ against a reference dataset that contained all Uniprot sequences of the genes listed in ${ }^{124,125}$ (Supplementary Table 9 and Supplementary file 5). Catabolic pathways of other two sulfur-metabolites, 2,3-dihydroxypropane-1-sulfonate (DHPS) and taurine, were identified

472 aminotransferase (tpa gene; K03851) or via taurine dehydrogenase (tauXY genes; K07255+K07256), fol-

473 lowed by a sulfoacetaldehyde acetyltransferase (xsc gene; K03852) ${ }^{126}$.

\section{KEGG module reconstruction}

475 KEGG orthologies (KOs) annotations generated by kofamscan were recombined in KEGG modules (KMs) us-

476 ing an in-house R script. The KMs represent minimal functional units describing either pathways, structural 
bioRxiv preprint doi: https:/doi.org/10.1101/2020.06.30179929: this version posted June 28,2021 . The copyright holder for this preprint (which was not certified by peer review) is the author/funder, who has granted bioRxiv a license to display the preprint in perpetuity. It is made available under aCC-BY-NC-ND 4.0 International license.

477 complexes (e.g. transmembrane pump or ribosome), functional sets (essential sets as Aminoacyl-tRNA syn-

478 thases or nucleotide sugar biosynthesis) or signaling modules (phenotypic markers as pathogenicity). Briefly,

479 using the R implementation of KEGG REST API ${ }^{127}$, the script fetches the diagrams of all KMs from the KEGG

480 website. Each diagram represents a reactions' scheme of a KM listing all known KOs that can perform each

481 of the reactions necessary to complete that scheme (Supplementary Fig. 1b). The completeness of a KM in

482 a genome was assessed as the number of required reactions for which at least one KOs was annotated and

483 only complete KMs were retained in downstream analyses (e.g., a KM with 7 out of 8 reactions is incom-

484 plete and would be discarded). However, to partially compensate for possible annotation issues, one miss-

485 ing reaction was allowed in KMs with $\geq 3$ reactions (i.e., a KM with 7 out of 8 annotated reactions is con-

486 sidered complete; see Supplementary text and Supplementary Table 10 for more details).

\section{Genetic and interaction traits identification}

488 The annotated complete KMs, secondary metabolites, phytohormones and transporters represent the ge-

489 netic traits identified in the genomes ( 556 genetic traits). From this list, the subset of interaction traits was

490 manually extracted based on current knowledge about processes that likely play a role in microbial interac-

491 tions (list of picked interaction traits in Supplementary Table 2). Within the KMs we identified traits related

492 to vitamin biosynthetic pathways, quorum sensing, chemotaxis, antimicrobial resistance, motility and adhe-

493 sion (Supplementary Table 5). Since the ecological role of most secondary metabolites is still unclear, a care-

494 ful literature search was performed to identify and retain only the secondary metabolite clusters with a pro-

495 posed function which can be linked to microbial interaction processes, such as siderophore production,

496 quorum sensing and antimicrobial compound biosynthesis (Supplementary Table 6). The phytohormone an-

497 notations revealed the capability of producing indoleacetic acid (auxin) through four different pathways

498 (Supplementary Table 8). Vitamin and siderophore transporters were identified in the transporter annota-

499 tions looking for the related transporter families (e.g. TonB, Btu) and the substrate information (Supple-

500 mentary Table 4). 


\section{Mapping to environmental datasets}

502 The selected datasets represent amplicon time series generated with Illumina sequencing of the V4 region

503 of the $16 \mathrm{~S}$ rDNA of bacterial communities sampled in a coastal (between 1-5m of depth, Canoe Cove, Na-

504 hant, MA, USA) ${ }^{59}$ and a pelagic (between $10-500 \mathrm{~m}$ of depth, n-1200 station, Easter Mediterranean sea)

$505{ }^{60}$ site. Mapping between the full 16S rDNAs extracted from genomes and amplicon sequences was per-

506 formed with BLAST (blastn v2.9.0, e-value <1e-5) using different identity threshold to filter the best hits:

$507100 \%, 97 \%, 94.5 \%$ and $86.5 \%$. The first two values represent a new proposed threshold and the most com -

508 monly used threshold to define operational taxonomic units (OTUs) ${ }^{128}$, while the last two values were sug-

509 gested as threshold to classify OTUs at genus and family levels ${ }^{129}$. In addition, for each identity threshold we

510 inspected the top blast hits (up to 20) and calculate a mapping specificity index as the number of hits as-

511 signed to a same GFC over the total number of hits (Supplementary Fig.s 4a and 5a). To avoid spurious map -

512 ping, we only retained in downstream analyses sequences with a specificity index $=1$ (i.e. all best blast hits

513 belonged to the same GFC).

514 The evaluation of the GFC concept was performed by using the coastal time series, because it offers a high

515 (daily) temporal resolution of changes in the bacterial community composition and the authors applied a

516 time deconvolution analysis to characterize the OTU temporal dynamics ${ }^{59}$. The OTUs included in the decon-

517 volution analysis represented $\sim 97 \%$ of the total sequences in the dataset and for each pair of OTUs, the au-

518 thors calculated the frequency interaction score (the higher the score, the more synchronous were the tem-

519 poral dynamics of both OTUs, and vice-versa). From the list of all pairs, we only considered OTU pairs for

520 which at least one of the two OTUs mapped to a GFC. We wanted to exclude cases of OTUs pairs that could

521 belong to a same, but yet unknown, GFC. To test for the GFC concept, we compared the frequency interac -

522 tion score between OTU pairs mapped to the same OTU (i.e. both OTUs mapped to the same GFC) versus

523 OTU pairs mapped to different GFCs (e.g. the two OTUs mapped to different GFCs, or one of the OTU was

524 unmapped). For each identity threshold, the normal distribution of the frequency interaction score was as-

525 sessed with the Shapiro test ( $r$ 's function shapiro.test; p.values $<<0.001$ ), and t-test ( $r$ 's function t.test) was

526 performed to test for a significant difference in the mean ranks between the two groups of OTU pairs. We 
527 repeated the test by randomly assigning OTU pairs to the "same GFC" and "different GFC" groups by keep -

528 ing the same group sizes and by creating two groups of equal size.

\section{Statistical analyses}

530 The presence/absence matrix of genetic traits across genomes served as basis to cluster the former into

531 linked trait clusters (LTCS) and the latter into genome functional clusters (GFCs). Both clustering approaches

532 implemented the Pearson coefficient $r$ (also known as phi coefficient when applied to dichotmous variables)

533 to calculate the genome and trait correlation matrices. While no pair of genomes scored a negative $r$ value

534 (as they all shared some "core" functional traits), negative correlations between pairs of genetic traits were

535 threshold to zeros to ensure that the trait clustering was only driven by positive correlation. Moreover, only

536 pairwise correlations with a FDR-corrected $\mathrm{p}$-value $<0.05$ (chi-square test, $\mathrm{df}=1$ ) were retained. The parsed

537 correlation matrices were fed as similarity matrices into the affinity propagation algorithm implemented

538 with the apcluster function ( $q=0.5 ; r$ package apcluster $)^{130}$. This machine learning algorithm was chosen be-

539 cause it does not require the number of clusters to be determined a priori, allowing instead this feature to

540 emerge from the data ${ }^{131}$. Briefly, a functional similarity matrix is used to construct a network where nodes

541 and edges are known to be genomes (or genetic traits) and their pairwise $r$ correlation, respectively. Starting

542 from a random set of exemplar nodes, clusters are created by expansion towards the adjoining, most sim-

543 ilar, nodes. Through iterations of this procedure, the algorithm tries to maximize the total similarity

544 between nodes within each cluster, eventually converging towards the best set of clusters. Clustering ro-

545 bustness and accuracy of both GFCs and LTCs were tested by performing a sensitivity analysis of the ' $q$ '

546 parameter which controls the clustering sensitivity in the apcluster function, and by down-sampling

547 overrepresented taxa at $80 \%, 60 \%$ and $40 \%$ of their genome coverage (see Supplementary information and

548 Supplementary Fig. 15).

549 For the LTC delineation, genetic traits were pre-filtered to remove noisy signals and only traits found in $\geq 3 \%$

550 of the genomes ( $\geq 14$ genomes) were used in the clustering (i.e. 379 genetic traits out of 578 in total). Sim-

551 ilar to the context of linkage disequilibrium ${ }^{132}, r$ indicates non-random association between genetic traits 
552 because those traits are interactively linked to fitness, or simply because they are closely located on the

553 chromosome (i.e. lower chances of recombination). However, as the genetic traits analysed commonly in-

554 volve multiple genes, the second possibility is less likely. While exploring the functional potential, a LTC was

555 considered complete in a genome when $>50 \%$ of the grouped genetic traits were present and it was con-

556 sidered complete in a GFC when the average completeness of the included genomes was $>50 \%$. The genetic

557 traits belonging to LTCs that were never found to be complete in at least one GFC were considered as un -

558 clustered.

\section{Authors' contributions}

LZ, DS and H-PG designed the research. LZ and DS analyzed the data. TM contributed with analytic tools. LZ wrote the paper with substantial revisions from DS, DSegrè and H-PG. All authors read and approved the final manuscript.

\section{Competing interests}

566 The authors declare that they have no competing interests.

\section{Availability of data and material}

568 All genomes are available in the online repositories of NCBI and JGI under the accession codes listed in Sup-

569 plementary Table 3. The codes for functional annotation, reconstruction of KEGG modules and statistical analysis are available on GitHub (https://github.com/lucaz88/genome_comparison_code).

\section{Acknowledgements}

572 This work was supported by the Human Frontier Science Program (HFSP) through the grant number RGB

573 0020/2016. We thank Anna Godhe, Mats Töpel and Oskar Johansson for providing early access to some of

574 the genomes included in the analysis. We thank the entire IAMM team (Dikla Aharonovich, David Bernstein, 
bioRxiv preprint doi: https:/doi.org/10.1101/2020.06.30179929: this version posted June 28,2021 . The copyright holder for this preprint (which was not certified by peer review) is the author/funder, who has granted bioRxiv a license to display the preprint in perpetuity. It is made available under aCC-BY-NC-ND 4.0 International license.

Falk Eigemann, Elena Forchielli, Tal Luzzatto-Knaan, Shany Ofaim, Melissa Osborne, Solvig Pinnow, Dalit Roth-Rosenberg, Angela Vogts and Maren Voss) for the constructive discussions and ideas that led us to shape this manuscript. A sincere thank you to Silvia Munari for her diligent proofreading of this manuscript.

\section{References}

1. Hibbing, M. E., Fuqua, C., Parsek, M. R. \& Peterson, S. B. Bacterial competition: Surviving and thriving in the microbial jungle. Nature Reviews Microbiology vol. 8 15-25 (2010).

2. Zimmerman, A. E. et al. Metabolic and biogeochemical consequences of viral infection in aquatic ecosystems. Nat. Rev. Microbiol. 18, 21-34 (2020).

3. Bjorbækmo, M. F. M., Evenstad, A., Røsæg, L. L., Krabberød, A. K. \& Logares, R. The planktonic protist interactome: where do we stand after a century of research? ISME J. 14, 544-559 (2020).

4. Amin, S. A., Parker, M. S. \& Armbrust, E. V. Interactions between diatoms and bacteria. Microbiol. Mol. Biol. Rev. 76, 667-84 (2012).

5. Seymour, J. R., Amin, S. A., Raina, J.-B. \& Stocker, R. Zooming in on the phycosphere: the ecological interface for phytoplankton-bacteria relationships. Nat. Microbiol. 2, 17065 (2017).

6. Farooq Azam and Francesca Malfatti. Microbial structuring of marine ecosystems. Nat. Rev. Microbiol. 5, 782-791 (2007).

7. Zoccarato, L. \& Grossart, H.-P. Relationship Between Lifestyle and Structure of Bacterial Communities and Their Functionality in Aquatic Systems. in Advances in Environmental Microbiology - The Structure and Function of Aquatic Microbial Communities (ed. Hurst, C. J.) 13-52 (Springer Nature Switzerland AG 2019, 2019). doi:10.1007/978-3-030-16775-2_2.

8. Kirchman, D. L. Processes in Microbial Ecology. (Oxford University Press, 2012). doi:10.1093/ acprof:oso/9780199586936.001.0001.

9. Worden, A. Z. et al. Rethinking the marine carbon cycle: Factoring in the multifarious lifestyles of microbes. Science (80-. ). 347, 1257594 (2015).

10. Gibert, J. P. Temperature directly and indirectly influences food web structure. Sci. Rep. 9, 5312 (2019).

11. Levine, J. M., Bascompte, J., Adler, P. B. \& Allesina, S. Beyond pairwise mechanisms of species coexistence in complex communities. Nature 546, 56-64 (2017).

12. Bell, W. \& Mitchell, R. Chemotactic and Growth Responses of Marine Bacteria to Algal Extracellular Products. Biol. Bull. 143, 265-277 (1972).

13. Amin, S. A. et al. Interaction and signalling between a cosmopolitan phytoplankton and associated bacteria. Nature 522, 98-101 (2015). 
608 14. Durham, B. P. et al. Cryptic carbon and sulfur cycling between surface ocean plankton. Proc. Natl. Acad. Sci. 112, 453-457 (2015).

610 15. Durham, B. P. et al. Sulfonate-based networks between eukaryotic phytoplankton and heterotrophic bacteria in the surface ocean. Nat. Microbiol. 4, 1706-1715 (2019).

612 16. Moran, M. A. \& Durham, B. P. Sulfur metabolites in the pelagic ocean. Nature Reviews Microbiology vol. 17 665-678 (2019).

17. Paul, C., Mausz, M. A. \& Pohnert, G. A co-culturing/metabolomics approach to investigate chemically mediated interactions of planktonic organisms reveals influence of bacteria on diatom metabolism. Metabolomics 9, 349-359 (2013).

18. Segev, E. et al. Dynamic metabolic exchange governs a marine algal-bacterial interaction. Elife 5, e17473 (2016).

19. Christie-Oleza, J. A., Sousoni, D., Lloyd, M., Armengaud, J. \& Scanlan, D. J. Nutrient recycling facilitates long-term stability of marine microbial phototroph-heterotroph interactions. Nat. Microbiol. 2, 17100 (2017).

20. Wang, H., Tomasch, J., Jarek, M. \& Wagner-Döbler, I. A dual-species co-cultivation system to study

21. Amin, S. A. et al. Photolysis of iron-siderophore chelates promotes bacterial-algal mutualism. Proc.

22. Keshtacher-Liebso, E., Hadar, Y. \& Chen, Y. Oligotrophic Bacteria Enhance Algal Growth under Iron-

23. van Tol, H. M., Amin, S. A. \& Armbrust, E. V. Ubiquitous marine bacterium inhibits diatom cell divi-

24. Seyedsayamdost, M. R., Case, R. J., Kolter, R. \& Clardy, J. The Jekyll-and-Hyde chemistry of Phaeobac-

25. Grossart, H.-P. et al. Interactions between marine snow and heterotrophic bacteria: Aggregate formation and microbial dynamics. Aquat. Microb. Ecol. 42, 19-26 (2006).

26. Aharonovich, D. \& Sher, D. Transcriptional response of Prochlorococcus to co-culture with a marine Alteromonas: differences between strains and the involvement of putative infochemicals. ISME J. 115 (2016) doi:10.1038/ismej.2016.70.

27. Coe, A. et al. Survival of Prochlorococcus in extended darkness. Limnol. Oceanogr. 61, 1375-1388

639 28. Hou, S. et al. Benefit from decline: The primary transcriptome of Alteromonas macleodii str. Te101 collective diversity. Nat. Rev. Microbiol. 13, 13-27 (2015). 
bioRxiv preprint doi: https:/doi.org/10.1101/2020.06.30179929: this version posted June 28,2021 . The copyright holder for this preprint (which was not certified by peer review) is the author/funder, who has granted bioRxiv a license to display the preprint in perpetuity. It is made available under aCC-BY-NC-ND 4.0 International license.

643 30. Cordero, O. X. et al. Population Genomics of Early Events in the Ecological Differentiation of Bacteria. Science (80-. ). 336, 48-51 (2012).

645 31. Tai, V., Paulsen, I. T., Phillippy, K., Johnson, D. A. \& Palenik, B. Whole-genome microarray analyses of

32. Long, R. A. \& Azam, F. Antagonistic interactions among marine bacteria. Appl. Environ. Microbiol. 67,

33. Sher, D., Thompson, J. W., Kashtan, N., Croal, L. \& Chisholm, S. W. Response of Prochlorococcus eco-

34. Grossart, H.-P., Schlingloff, A., Bernhard, M., Simon, M. \& Brinkhoff, T. Antagonistic activity of bacteria isolated from organic aggregates of the German Wadden Sea. FEMS Microbiol. Ecol. 47, 387396 (2004).

35. Snel, B., Bork, P. \& Huynen, M. A. Genome phylogeny based on gene content. Nat. Genet. 21, 108110 (1999).

36. Espariz, M., Zuljan, F. A., Esteban, L. \& Magni, C. Taxonomic identity resolution of highly phylogenetically related strains and selection of phylogenetic markers by using genome-scale methods: The ba-

37. Hernández-González, I. L., Moreno-Hagelsieb, G. \& Olmedo-Álvarez, G. Environmentally-driven gene

38. Pachiadaki, M. G. et al. Charting the Complexity of the Marine Microbiome through Single-Cell Gen-

39. Lauro, F. M. et al. The genomic basis of trophic strategy in marine bacteria. Proc. Natl. Acad. Sci. 106,

40. Newton, R. J. et al. Genome characteristics of a generalist marine bacterial lineage. ISME J. 4, 784-

41. Krause, S. et al. Trait-based approaches for understanding microbial biodiversity and ecosystem func-

42. Bordron, P. et al. Putative bacterial interactions from metagenomic knowledge with an integrative

43. Raina, J.-B., Fernandez, V., Lambert, B., Stocker, R. \& Seymour, J. R. The role of microbial motility and

44. Holmström, C. \& Kjelleberg, S. Marine Pseudoalteromonas species are associated with higher organisms and produce biologically active extracellular agents. FEMS Microbiol. Ecol. 30, 285-293 (1999). Bacteria from the North Sea. Appl. Environ. Microbiol. 66, 3044-3051 (2000). 
47. Sonnenschein, E. C., Syit, D. A., Grossart, H.-P. \& Ullrich, M. S. Chemotaxis of Marinobacter adhaerens and its impact on attachmentto the diatom Thalassiosira weissflogii. Appl. Environ. Microbiol. 78, 6900-6907 (2012).

48. Langille, M. G. I. et al. Predictive functional profiling of microbial communities using $16 \mathrm{~S}$ rRNA marker gene sequences. Nat. Biotechnol. 31, 814-821 (2013).

49. Maistrenko, O. M. et al. Disentangling the impact of environmental and phylogenetic constraints on prokaryotic within-species diversity. ISME J. 14, 1247-1259 (2020).

50. Chaumeil, P. A., Mussig, A. J., Hugenholtz, P. \& Parks, D. H. GTDB-Tk: A toolkit to classify genomes with the genome taxonomy database. Bioinformatics 36, 1925-1927 (2020).

51. Sunagawa, S. et al. Structure and function of the global ocean microbiome. Science 348, 1261359 (2015).

52. Louca, S., Parfrey, L. W. \& Doebeli, M. Decoupling function and taxonomy in the global ocean microbiome. Science (80-. ). 353, 1272-1277 (2016).

53. Falkowski, P. G., Fenchel, T. \& Delong, E. F. The microbial engines that drive earth's biogeochemical cycles. Science (80-. ). 320, 1034-1039 (2008).

54. Martiny, J. B. H., Jones, S. E., Lennon, J. T. \& Martiny, A. C. Microbiomes in light of traits: A phylogenetic perspective. Science (80-. ). 350, aac9323 (2015).

55. Hunt, D. E. et al. Resource Partitioning and Sympatric Differentiation Among Closely Related Bacterioplankton. Science (80-. ). 320, (2008).

56. Teeling, H. et al. Recurring patterns in bacterioplankton dynamics during coastal spring algae blooms. Elife 5, (2016).

57. Arias-Andres, M., Klümper, U., Rojas-Jimenez, K. \& Grossart, H. P. Microplastic pollution increases gene exchange in aquatic ecosystems. Environ. Pollut. 237, 253-261 (2018).

58. Galand, P. E., Pereira, O., Hochart, C., Auguet, J. C. \& Debroas, D. A strong link between marine microbial community composition and function challenges the idea of functional redundancy. ISME J. 12, 2470-2478 (2018).

59. Martin-Platero, A. M. et al. High resolution time series reveals cohesive but short-lived communities in coastal plankton. Nat. Commun. 9, 1-11 (2018).

60. Rosenberg, D. R. et al. Particle-associated and free-living bacterial communities in an oligotrophic sea are affected by different environmental and anthropogenic factors. bioRxiv 2020.04.20.051391 (2020) doi:10.1101/2020.04.20.051391.

61. Grote, J. et al. Streamlining and core genome conservation among highly divergent members of the SAR11 clade. MBio 3, e00252-12 (2012).

62. Shih, P. M. et al. Improving the coverage of the cyanobacterial phylum using diversity-driven genome sequencing. Proc. Natl. Acad. Sci. 110, 1053-1058 (2013). 
714

715

716

63. Croft, M. T., Warren, M. J. \& Smith, A. G. Algae Need Their Vitamins. Eukaryot. Cell 5, 1175-1183 (2006).

64. Romine, M. F., Rodionov, D. A., Maezato, Y., Osterman, A. L. \& Nelson, W. C. Underlying mechanisms for syntrophic metabolism of essential enzyme cofactors in microbial communities. ISME J. 11, 14341446 (2017).

65. Suffridge, C. P. et al. B Vitamins and Their Congeners as Potential Drivers of Microbial Community Composition in an Oligotrophic Marine Ecosystem. J. Geophys. Res. Biogeosciences 123, 2890-2907 (2018).

66. Sañudo-Wilhelmy, S. A. et al. Multiple B-vitamin depletion in large areas of the coastal ocean. Proc. Natl. Acad. Sci. 109, 14041-14045 (2012).

67. Browning, T. J. et al. Nutrient co-limitation at the boundary of an oceanic gyre. Nature 551, 242-246 (2017).

68. Morris, J. et al. The Black Queen Hypothesis: Evolution of Dependencies through Adaptive Gene Loss. MBio 3, e00036 (2012).

69. Fang, H., Kang, J. \& Zhang, D. Microbial production of vitamin B12: A review and future perspectives. Microb. Cell Fact. 16, 1-14 (2017).

70. Jurgenson, C. T., Begley, T. P. \& Ealick, S. E. The Structural and Biochemical Foundations of Thiamin Biosynthesis. Annu. Rev. Biochem. 78, 569-603 (2009).

71. McRose, D. et al. Alternatives to vitamin B1 uptake revealed with discovery of riboswitches in multiple marine eukaryotic lineages. ISME J. 8, 2517-2529 (2014).

72. Vraspir, J. M. \& Butler, A. Chemistry of Marine Ligands and Siderophores. Ann. Rev. Mar. Sci. 1, 43-63 (2009).

73. De Smet, I. et al. Unraveling the evolution of auxin signaling. Plant Physiol. 155, 209-21 (2011).

74. Morrissey, J. \& Bowler, C. Iron utilization in marine cyanobacteria and eukaryotic algae. Front. Microbiol. 3, 43 (2012).

75. Kazamia, E. et al. Endocytosis-mediated siderophore uptake as a strategy for Fe acquisition in diatoms. Sci. Adv. 4, eaar4536 (2018).

76. Gärdes, A. et al. Detection of photoactive siderophore biosynthetic genes in the marine environment. BioMetals 26, 507-516 (2013).

77. Yarimizu, K. et al. Distribution of dissolved iron and bacteria producing the photoactive siderophore, vibrioferrin, in waters off Southern California and Northern Baja. BioMetals 32, 139-154 (2019).

78. Madhusoodanan, J. Can single molecules bind together entire ecosystems? Proc. Natl. Acad. Sci. U. S. A. 113, 10451-10452 (2016).

79. Coale, T. H. et al. Reduction-dependent siderophore assimilation in a model pennate diatom. Proc. Natl. Acad. Sci. 116, 23609-23617 (2019). 
80. Basu, S., Gledhill, M., de Beer, D., Prabhu Matondkar, S. G. \& Shaked, Y. Colonies of marine cyanobacteria Trichodesmium interact with associated bacteria to acquire iron from dust. Commun. Biol. 2, 18 (2019).

81. Kramer, J., Özkaya, Ö. \& Kümmerli, R. Bacterial siderophores in community and host interactions. Nature Reviews Microbiology vol. 18 152-163 (2020).

82. Patten, C. L., Blakney, A. J. C. \& Coulson, T. J. D. Activity, distribution and function of indole-3-acetic

83. Long, R. A. et al. Antagonistic interactions among marine bacteria impede the proliferation of Vibrio acid biosynthetic pathways in bacteria. Crit. Rev. Microbiol. 39, 395-415 (2012).

84. Long, R. A., Qureshi, A., Faulkner, D. J. \& Azam, F. 2-n-pentyl-4-quinolinol produced by a marine Alteromonas sp. and its potential ecological and biogeochemical roles. Appl. Environ. Microbiol. 69, 568-576 (2003).

86. Robinson, S. L., Christenson, J. K. \& Wackett, L. P. Biosynthesis and chemical diversity of $\beta$-lactone

87. Cotter, P. D., Ross, R. P. \& Hill, C. Bacteriocins-a viable alternative to antibiotics? Nature Reviews Mi-

88. Guo, L. et al. Lipid A Acylation and Bacterial Resistance against Vertebrate Antimicrobial Peptides sys-

89. Hinz, A., Lee, S., Jacoby, K. \& Manoil, C. Membrane proteases and aminoglycoside antibiotic resist-

90. Yasser, E.-N. \& Adli, A. Toxicity of Single and Mixtures of Antibiotics to Cyanobacteria. J. Environ.

92. Grohmann, E., Christie, P. J., Waksman, G. \& Backert, S. Type IV secretion in Gram-negative and

93. Guillemette, R., Ushijima, B., Jalan, M., Häse, C. C. \& Azam, F. Insight into the resilience and suscept-

94. Cianfanelli, F. R., Monlezun, L. \& Coulthurst, S. J. Aim, Load, Fire: The Type VI Secretion System, a terial type-III secretion system effectors. Current Opinion in Microbiology vol. 23 14-22 (2015). 
bioRxiv preprint doi: https:/doi.org/10.1101/2020.06.30179929: this version posted June 28,2021 . The copyright holder for this preprint (which was not certified by peer review) is the author/funder, who has granted bioRxiv a license to display the preprint in perpetuity. It is made available under aCC-BY-NC-ND 4.0 International license.

96. Pellegrini, M., Marcotte, E. M., Thompson, M. J., Eisenberg, D. \& Yeates, T. O. Assigning protein functions by comparative genome analysis: Protein phylogenetic profiles. Proc. Natl. Acad. Sci. U. S. A. 96, 4285-4288 (1999).

97. Liu, C., Wright, B., Allen-Vercoe, E., Gu, H. \& Beiko, R. Phylogenetic Clustering of Genes Reveals Shared Evolutionary Trajectories and Putative Gene Functions. Genome Biol. Evol. 10, 2255-2265 (2018).

98. Siegel, L. M., Murphy, M. J. \& Kamin, H. Reduced nicotinamide adenine dinucleotide phosphatesulfite reductase of enterobacteria. I. The Escherichia coli hemoflavoprotein: molecular parameters and prosthetic groups. J. Biol. Chem. 248, 251-264 (1973).

99. Scott, A. I., Irwin, A. J., Siegel, L. M. \& Shoolery, J. N. Sirohydrochlorin. Prosthetic Group of a Sulfite Reductase Enzyme and Its Role in the Biosynthesis of Vitamin B12. Journal of the American Chemical Society vol. 100 316-318 (1978).

100. Bali, S. et al. Molecular hijacking of siroheme for the synthesis of heme and $\mathrm{d} 1 \mathrm{~h}$ heme. Proc. Natl. Acad. Sci. 108, 18260-18265 (2011).

101. Cook, A. M., Smits, T. H. M. \& Denger, K. Sulfonates and Organotrophic Sulfite Metabolism. in Microbial Sulfur Metabolism 170-183 (Springer Berlin Heidelberg, 2008). doi:10.1007/978-3-540-726821_14.

102. Zere, T. R. et al. Genomic targets and features of BarA-UvrY (-SirA) signal transduction systems. PLoS One 10, e0145035 (2015).

103. Huang, L., Xu, W., Su, Y., Zhao, L. \& Yan, Q. Regulatory role of the RstB-RstA system in adhesion, biofilm production, motility, and hemolysis. Microbiologyopen 7, e00599 (2018).

104. Rolland, J. L., Stien, D., Sanchez-Ferandin, S. \& Lami, R. Quorum Sensing and Quorum Quenching in the Phycosphere of Phytoplankton: a Case of Chemical Interactions in Ecology. J. Chem. Ecol. 1-11 (2016) doi:10.1007/s10886-016-0791-y.

105. Chen, J. et al. The UhpA mutant of Edwardsiella piscicida enhanced its motility and the colonization in the intestine of tilapia. Fish Shellfish Immunol. 104, 587-591 (2020).

106. Janda, J. M. \& Abbott, S. L. The genus Aeromonas: Taxonomy, pathogenicity, and infection. Clin. Microbiol. Rev. 23, 35-73 (2010).

107. Darshanee Ruwandeepika, H. A. et al. Pathogenesis, virulence factors and virulence regulation of vibrios belonging to the Harveyi clade. Rev. Aquac. 4, 59-74 (2012).

108. Murthy, K. N., Mohanraju, R., Karthick, P. \& Ramesh, C. Phenotypic and molecular characterization of epiphytic vibrios from the marine macro algae of Andaman Islands, India. Indian J. Geo-Marine Sci. 45, 304-309 (2016).

109. van Mastrigt, O., Mager, E. E., Jamin, C., Abee, T. \& Smid, E. J. Citrate, low pH and amino acid limitation induce citrate utilization in Lactococcus lactis biovar diacetylactis. Microb. Biotechnol. 11, 369380 (2018). 
822 110. Wang, H. et al. Identification of Genetic Modules Mediating the Jekyll and Hyde Interaction of Dinoroseobacter shibae with the Dinoflagellate Prorocentrum minimum. Front. Microbiol. 6, 1262 (2015).

824 111. Frosch, M., Edwards, U., Bousset, K., Krauße, B. \& Weisgerber, C. Evidence for a common molecular

112. Chen, D., Shao, Q., Yin, L., Younis, A. \& Zheng, B. Polyamine function in plants: Metabolism, regulation on development, and roles in abiotic stress responses. Frontiers in Plant Science vol. 91945 (2019).

114. Russel, J., Røder, H. L., Madsen, J. S., Burmølle, M. \& Sørensen, S. J. Antagonism correlates with quality of microbial genomes recovered from isolates, single cells, and metagenomes. Genome Res.

116. Bowers, R. M. et al. Minimum information about a single amplified genome (MISAG) and a metagen-

117. Seemann, T. Prokka: Rapid prokaryotic genome annotation. Bioinformatics 30, 2068-2069 (2014).

118. Aramaki, T. et al. KofamKOALA: KEGG Ortholog assignment based on profile HMM and adaptive

119. Blin, K. et al. AntiSMASH 5.0: Updates to the secondary metabolite genome mining pipeline. Nucleic

120. Zhang, P. et al. The distribution of tryptophan-dependent indole-3-acetic acid synthesis pathways in

121. Reddy, V. S. \& Saier, M. H. BioV Suite - A collection of programs for the study of transport protein

122. Amin, S. A., Green, D. H., Waheeb, D. Al, Gärdes, A. \& Carrano, C. J. Iron transport in the genus Marinobacter. BioMetals 25, 135-147 (2012).

123. Tanabe, T. et al. Identification and Characterization of Genes Required for Biosynthesis and Transport

124. Moran, M. A., Reisch, C. R., Kiene, R. P. \& Whitman, W. B. Genomic Insights into Bacterial DMSP Transformations. Ann. Rev. Mar. Sci. 4, 523-542 (2012). ine phytoplankton and bacteria. Front. Microbiol. 8, 637 (2017). 
857 126. Cook, A. M. \& Denger, K. Metabolism of taurine in microorganisms: a primer in molecular biod858 iversity? in Advances in Experimental Medicine and Biology (ed. Oja, S. S.) 3-13 (Springer New York, 859 2006). doi:10.1007/978-0-387-33504-9_1.

860 127. Tenenbaum, D. KEGGREST: Client-side REST access to KEGG. R package version 1.29.0. (2020).

861 128. Edgar, R. C. Updating the $97 \%$ identity threshold for 16 S ribosomal RNA OTUs. Bioinformatics 34, $862 \quad$ 2371-2375 (2018).

863 129. Yarza, P. et al. Uniting the classification of cultured and uncultured bacteria and archaea using $16 \mathrm{~S}$ rRNA gene sequences. Nat. Rev. Microbiol. 12, 635-645 (2014).

865 130. Bodenhofer, U., Kothmeier, A. \& Hochreiter, S. Apcluster: an R package for affinity propagation clustering. Bioinformatics 27, 2463-2464 (2011).

131. Frey, B. J. \& Dueck, D. Clustering by passing messages between data points. Science (80-. ). 315, $972-$ 868976 (2007).

869 132. Kimura, M. Theoretical foundation of population genetics at the molecular level. Theor. Popul. Biol. 870 2, 174-208 (1971).

871 133. R Core Team. R: A Language and Environment for Statistical Computing. (2021). 